Creating Productive and Upcoming Sport Education Profesional Hmzanwadi University

Vol.3, No.2, Desember 2020, Hal. 127-133

e-ISSN 2614-8781

\title{
PENGARUH TINGKAT DEHIDRASI TERHADAP VOLUME LATIHAN ATLET PENCAK SILAT
}

\author{
Galih Baskara ${ }^{1}$, Muhammad Husni Tamim ${ }^{2}$, Rina Nopiana ${ }^{3}$ \\ Email: galihbaskara@gmail.com ${ }^{1}$, husnitamim0@gmail.com ${ }^{2}, \underline{\text { nopianar@gmail.com }}{ }^{3}$ \\ 1,2,3 Program studi Penjaskesrek, Fakultas Ilmu Pendidikan, Universitas Hamzanwadi
}

\begin{abstract}
Abstrak
Status hidrasi yang baik dapat dicapai atlet dengan mengkonsumsi cairan yang cukup sebelum, selama dan setelah latihan. Pemberian cairan selama masa latihan dan pertandingan sangat penting untuk mempertahankan status hidrasi atau menjaga keseimbangan air dan elektrolit. penelitian ini bertujuan untuk Menganalisis pengaruh tingkat hidrasi dengan volume latihan. Penelitian ini merupakan penelitian kuantitatif dengan mengunakan metode deskriptif, teknik sampeling yang digunakan dalam penelitian ini adalah teknik sampeling jenuh dengan sampel penelitian berjumlah 13 atlet dan penelitian ini dilakukan di padepokan perguruan silat Macan Lemuring. teknik sampeling jenuh adalah penentuan teknik sampeling bila semua anggota populasi digunakan sebagai sampel, dalam penelitian ini sampel yang diteliti berjumlah 13 atlet pencak silat, desain penelitian dalam penelitian adalah dengan mengambil data dari atlet yakni dengan mengambil data warna urine, kemudian dilakukan pengambilan data tingkat Vo2max dengan menghitung detak jantung atlet. Hasil penelitian bahwa atlet yang memiliki status hidrasi baik sebanyak 8 orang $(62 \%)$ dari jumlah sampel, sedangkan jumlah atlet yang memiliki status hidrasi sedang sebanyak 5 orang $(38 \%)$ dari sampel, dan tidak ditemukan atlet yang mengalami dehidrasi, atlet yang memiliki volume latihan tinggi sebanyak 9 atlet dari 13 atlet $(69 \%)$ dari sampel, sedangkan atlet yang memiliki volume latihan menengah sebanyak 4 atlet dari $13(31 \%)$, dan atlet yang memiliki volume latihan rendah dan kurang tidak ada,dan pengujian melalaui uji statistik, diketahui bahwa terdapat pengaruh yang signifikan antara tingkat hidrasi dengan volume latihan atlet, nilai sign sebesar 0,000 lebih kecil dari proabilitas 0,05 sehingga dapat disimpulkan bahwa Ho di tolak dan Ha diterima, yang berarti bahwa terdapat "pengaruh antara tingkat hidrasi dengan volume latihan".
\end{abstract}

Kata Kunci: Tingkat Hidrasi, Volume Latihan.

\begin{abstract}
The Good hydration status can be achieved by consuming adequate fluids before, during and after exercise. Administration of fluids during exercise and match is very important to maintain hydration status or maintain water and electrolyte balance. This study aims to analyze the effect of hydration level on exercise volume. This research is a quantitative research using descriptive method, the sampling technique used in this research is saturated sampling technique with a research sample of 13 athletes and this research was conducted at the Macan Lemuring silat college hermitage. Saturated sampling technique is the determination of the sampling technique when all members of the population are used as samples, in this study the samples studied were 13 athletes of pencak silat, the research design in this study was to take data from
\end{abstract}


athletes, namely by taking urine color data, then collecting data on Vo2max by counting the athlete's heart rate. The results showed that athletes who had good hydration status were 8 people (62\%) of the total sample, while the number of athletes who had moderate hydration status were 5 people (38\%) of the sample, and no athletes who were dehydrated, athletes who had volume 9 athletes out of 13 athletes (69\%) of the sample, while athletes who have medium training volume are 4 out of 13 (31\%), and athletes who have low and less exercise volume, and testing through statistical tests, It is known that there is a significant influence between the hydration level and the athlete's exercise volume, the sign value of 0.000 is smaller than the proability of 0.05, so it can be concluded that Ho is rejected and Ha is accepted, which means that there is an "influence between the level of hydration and the volume of exercise".

Keywords: hydration levels, exercise volume.

\section{A. Pendahuluan}

Putriana dalam Setiawati YN dkk (2012:49) menjelaskan bahwa atlet yang memulai latihan dengan status hidrasi yang baik belum tentu terhidrasi dengan baik pula setelah latihan. Status hidrasi yang baik dapat dicapai atlet dengan mengkonsumsi cairan yang cukup sebelum, selama dan setelah latihan. Pemberian cairan selama masa latihan dan pertandingan sangat penting untuk mempertahankan status dehidrasi atau menjaga keseimbangan air dan elektrolit. Sebuah penelitian di Brazil menunjukan bahwa 22\% atlet remaja ternyata masih mengkonsumsi air dibawah jumlah yang cukup (Sousa dalam Setiawati YN dkk, 2012:49). Kebutuhan gizi atlet perlu diperhatikan mengingat kebutuhan energi tubuhnya lebih tinggi dibandingkan non atlet. Kebutuhan gizi yang memadai dibutuhkan tidak hanya pada saat bertanding, tetapi pada saat latihan. Tidak ada yang khusus dalam asupan makanan atau diet saat latihan, namun ada beberapa hal yang perlu diawasi yaitu makanan sebaiknya bervariasi, jumlah lemak dan karbohidrat dalam makanan disesuaikan dengan kebutuhan atlet. Selain perlu diperhatikan asupan serat yang membantu kelancaran sistem pencernaan dan minum air putih yang cukup agar tidak timbul keluhan yang tidak diinginkan terutama bila latihan di lingkungan panas (Rahmawati dalam Setiawati YN dkk, 2012:49). Pada saat observasi awal yang dilakukan peneliti, yakni pada saat latihan di desa Kalijaga kecamatan Aik Mel, peneliti menemukan para atlet pencak silat perguruan Macan Lemuring sering mengalami kelelahan. Dan setelah bertemu pelatih yakni Pak Mukammal M.Pd, peneliti berhasil mendapatkan beberapa informasi tentang prestasi yang diraih para atlet dan kendala selama melakukan latihan, yakni pada saat melakukan latihan banyak atlet bahkan sebagian besarnya mengalami kelalahan lalu beristirahat sebelum waktu istirahat latihan. Berdasarkan latar belakang diatas memberikan suatu gambaran tentang masalah yang dihadapi. Masalah-maslah yang terdapat di atas dapat diidentifikasi sebagai berikut: Masih terdapat atlet yang mengalami dehidrasi atau kelelahan saat latihan, sparing maupun bertanding, Di perlukannya latihan yang efektif dan efisien dalam membentuk daya tahan fisik. Berdasarkan identifikasi masalah yang ditemukan banyak permasalah yang muncul dalam latihan, sparing maupun bertanding akan tetapi permasaalahan tidak mungkin akan di bahas secara detail. Oleh sebab itu, agar permasalahan lebih fokus dengan mempertimbangkan segala keterbatasan, maka penelitian ini hanya membahas tentang "Pengaruh Tingkat Hidrasi Terhadap Volume Latihan Atlet Pencak Silat Perguruan Macan Lemuring tahun 2020, Berdasar rumusan masalah tersebut, maka penelitian ini bertujuan untuk Menganalisis pengaruh tingkat hidrasi dengan volume latihan, 


\section{B. Metode}

Jenis penelitian yang digunakan dalam penelitian ini adalah penelitian kuantitatif. Metode penelitian kuantitatif merupakan salah satu jenis penelitian yang spesifikasinya adalah sistematis, terencana dan terstruktur dengan jelas sejak awal hingga pembuatan desain penelitiannya. Metode penelitian kuantitatif, sebagaimana dikemukakan oleh Sugiyono (2011: 8) yaitu: "Metode penelitian yang berlandaskan pada filsafat positivisme, digunakan untuk meneliti pada populasi atau sampel tertentu, pengumpulan data menggunakan instrumen penelitian, analisis data bersifat kuantitatif/statistik, dengan tujuan untuk menguji hipotesis yang telah ditetapkan". Penelitian ini menggunakan tipe penelitian deskriptif. Menurut Sugiyono (2011: 29), penelitian deskriptif adalah metode yang berfungsi untuk mendeskripsikan atau memberi gambaran terhadap obyek yang diteliti melalui data atau sampel yang telah terkumpul sebagaimana adanya, tanpa melakukan analisis dan membuat kesimpulan yang umum, Desain penelitian dari penelitian ini adalah dengan mengambil data dari status hidrasi dan data volume latihan, Data status hidrasi diperoleh dengan menggunakan sampel urin yang diambil sebelum latihan, atlet membuang air kecil kemudian air seni ditampung dalam gelas bening, Kemudian warna urin disesuaikan dengan indikator warna urin. Dan data dari Volume latihan diperoleh dengan mengecek denyut jamtumg permenit sebelum latihan, lalu memberikan latihan seperti biasa pada atlet namun sampai waktu $60 \%$ dari waktu latihan biasanya, dan setelah itu mengecek lagi denyut jantung sesudah memberikan latihan atau rangsangan $60 \%$ dari waktu latihan biasanya. Dan hasil dari volume latihan didapat dari rumus sebagai berikut : HR thrashold $=$ HR istirahat + 60\% (HR max - HR istirahat) Tirtawirya Devi (2012:96).

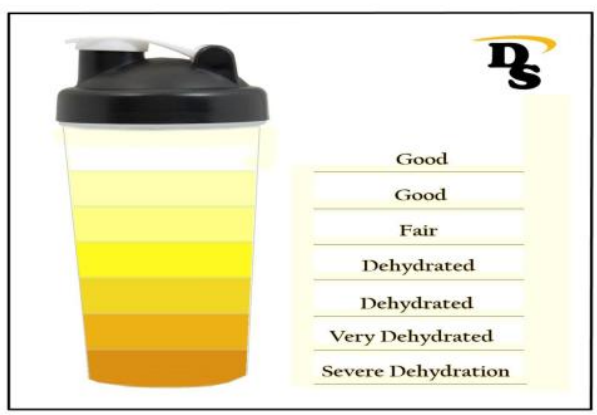

Gambar 1. Status Dehidrasi berdasar warna urin Sumber:www.google.com/search?q=urin+colour+chart\&client=firefoxa\&rls=org (dalam Cerika Rishmayanti,2014:57).

Adapun alat bantu dalam mengambil data adalah: Table tingkat Hidrasi., Stopwatch, Gelas bening pelastik. Sesuai dengan rancangan yang digunakan dalam penelitian ini yang dikaitkan dengan rumusan masalah dan tujuan penelitiannya, maka analisis statistik yang Pengaruh Tingkat Hidrasi Terhadap Volume Latihan Atlet Pencak Silat Perguruan Macan Lemuring 2020 adalah menggunakan analisis Regresi Sederhana, Regresi atau peramalan adalah didasarkan pada hubungan fumgsional ataupun kausal satu variabel independen dengan satu variabel dependen (Sugiyono, 2011:261). Berikut adalah analisis Regresi Sederhana dalam Penelitian ini:

$\mathrm{X} \longrightarrow \mathrm{Y}$ 


$$
\begin{aligned}
& \mathrm{Y}=\alpha+\mathrm{bX} \\
& \mathrm{X}=\text { Tingkat Hidrasi } \\
& \mathrm{Y}=\text { Volme Latihan }=\quad a=\frac{\cdot \sum \mathrm{Y}-\mathrm{B} \cdot \Sigma \mathrm{X}}{\mathrm{n} .} \quad \mathrm{b}=\frac{n \cdot \Sigma X Y-\cdot \Sigma X \cdot Y}{n \cdot \Sigma X^{2}-(\Sigma X)^{2}}
\end{aligned}
$$

Analisis Data adalah Uji Regresi Sederhana, Merumuskan Hipotesis Ha dan Ho, Teknik analisis data dalam penelitian ini menggunakan bantuan software SPSS 22.0. Penelitian ini dilakukan di Padepokan perguruan pencak silat Macan Lemuring yang berlokasi di Kalijaga Tengah, Kecamatan Aikmel, dan waktu penelitian pada bulan Februari-Maret 2020, Karena jumlah populasi atlet pencak silat perguruan macan lemuring berjumlah 13 orang, maka teknik sampeling yang digunakan dalam penelitian ini adalah teknik sampeling jenuh, Hal ini apabila jumlah populasi relative kecil, kurang dari 30 orang (Sugiyono, 2011:125).

\section{Hasil dan Pebahasan}

Penentuan status hidrasi responden pada penelitian ini berdasarkan pada hasil pengujian warna urin. Pengambilan sampel urin dilakukan sebelum atlet melakukan laihan, kemudian warna urin disesuaikan dengan indikator warna urin. Ketentuan indikator warna urin yaitu apabila 1-2 maka status hidrasi responden baik, 3 maka status hidrasi sedang, 4-5 maka status hidrasi adalah dehidrasi, 6 maka status dehidrasi adalah sangat dehidrasi, dan 7 maka status dehidrasi adalah dehidrasi berat. Dengan kategori tingkat hidrasi 1-2 =5, 3=4, 4-5 = 3, $6=2$,7= 1. Berikut adalah data status hidrasi atlet pencak silat pergurun macan lemuring:

Tabel 1. Data Status Hidrasi

\begin{tabular}{clccc} 
No & NAMA & L/P & STATUS HIDRASI & KATEGORI \\
\hline 1. & L.M.F & L & Baik & 1 \\
2. & A.H.G & L & Baik & 2 \\
3. & L.H & L & Baik & 2 \\
4. & A.Y & L & Baik & 2 \\
5. & M.F & L & Sedang & 3 \\
6. & J.A & L & Sedang & 3 \\
7. & F & L & Sedang & 3 \\
8. & M & P & Baik & 2 \\
9. & E.Z & P & Baik & 2 \\
10. & O & P & Sedang & 3 \\
11. & R & P & Sedang & 3 \\
12. & S.J & P & Baik & 2 \\
13. & A & P & Baik & 2 \\
\hline
\end{tabular}

Penentuan volume latihan responden dalam penelitian ini adalah dengan mengambil data denyut jantung, HR Max dan HR istirahat, kemudian menggunakan rumus Karvonen yakni HR thrashold $=\mathrm{HR}$ istirahat $+60 \%$ (HR max $-\mathrm{HR}$ istirahat), data HR Max diperoleh dengan cara 220 dikurangi usia dan data HR istirahat diperoleh dari mengecek denyut jantung sebelum latihan, ketentuan indikator hasil dari rumus ini yaitu : 1 rendah 120-150 denyutan permenit, 2 menengah 150-170 denyutan permenit, 3 tinggi 170-185 denyutan permenit, dan 4 maksimal lebih dari 185 denyutan permenit, jika intensitas latihan tinggi maka volume latihan rendah dan jika intensitas rendah maka volume latihan tinggi, Berikut adalah data volume latihan atlet pencak silat peguruan macan lemuring: 
Tabel 2. Data Volume Latihan

\begin{tabular}{clcccccc} 
No & Nama & $\mathrm{U}$ & $\begin{array}{c}\text { HR } \\
\max \end{array}$ & $\begin{array}{c}\text { HR } \\
\text { istirahat }\end{array}$ & $\begin{array}{c}\text { HR } \\
\text { thrashold }\end{array}$ & $\begin{array}{c}\text { Intensitas } \\
\text { latihan }\end{array}$ & $\begin{array}{c}\text { Volume } \\
\text { latihan }\end{array}$ \\
\hline 1. & L.M.F & 18 & 202 & 60 & 145 & 1 & 4 \\
2. & A.H.G & 18 & 202 & 65 & 147 & 1 & 4 \\
3. & L.H & 18 & 202 & 67 & 148 & 1 & 4 \\
4. & A.Y & 18 & 202 & 64 & 146 & 1 & 4 \\
5. & M.F & 18 & 202 & 75 & 151 & 2 & 3 \\
6. & J.A & 18 & 202 & 77 & 152 & 2 & 3 \\
7. & F & 18 & 202 & 65 & 147 & 1 & 4 \\
8. & M & 18 & 202 & 69 & 149 & 1 & 4 \\
9. & E.Z & 18 & 202 & 68 & 148,4 & 1 & 4 \\
10. & O & 18 & 202 & 77 & 152 & 2 & 3 \\
11. & R & 18 & 202 & 78 & 152,4 & 2 & 3 \\
12. & S.J & 18 & 202 & 70 & 149,2 & 1 & 4 \\
13. & A & 18 & 202 & 66 & 147,6 & 1 & 4 \\
\hline
\end{tabular}

Pengujian uji statistik dilakukan dengan bantuan software komputer SPSS 22.0, Hasil uji linieritas secara ringkas dapat dilihat pada tabel berikut ini.

Tabel 3. Descriptive Statistics

\begin{tabular}{|c|c|c|c|c|c|}
\hline & $\mathrm{N}$ & Minimum & Maximum & Mean & $\begin{array}{c}\text { Std. } \\
\text { Deviation }\end{array}$ \\
\hline Tingkat hidrasi & 13 & 4.00 & 5.00 & $\begin{array}{c}4.615 \\
4\end{array}$ & .50637 \\
\hline $\begin{array}{l}\text { Volume } \\
\text { latihan }\end{array}$ & 13 & 3.00 & 4.00 & $\begin{array}{c}3.692 \\
3\end{array}$ & .48038 \\
\hline $\begin{array}{c}\text { Valid N } \\
\text { (listwise) }\end{array}$ & 13 & & & & \\
\hline
\end{tabular}

Dari tabel di atas dijelaskan bahwa dengan jumlah data sebanyak 13 didapat niai minimum dari tingkat hidrasi sebesar 4 dan nilai maksimum sebesar 5 dengan nilai rata-rata sebesar 4,6 sedangkan variabel (Y) atau volume latihan memiliki nilai minimum sebesar 3 dan nilai maksimum sebesar 4 dengan nilai rata-rata sebesar 3,6.

Tabel 4. Hasil Uji Statistik Regresi Sederhana

\begin{tabular}{|c|c|c|c|c|c|}
\hline \multirow[b]{2}{*}{ Model } & \multicolumn{2}{|c|}{$\begin{array}{l}\text { Unstandardized } \\
\text { Coefficients }\end{array}$} & \multirow{2}{*}{$\begin{array}{l}\text { Standardized } \\
\text { Coefficients } \\
\text { Beta }\end{array}$} & \multirow[b]{2}{*}{$\mathrm{T}$} & \multirow[b]{2}{*}{ Sig. } \\
\hline & $\mathrm{B}$ & Std. Error & & & \\
\hline $1 \quad$ (Constant) & $-1.776 \mathrm{E}-15$ & .714 & & .000 & 1.000 \\
\hline Tingkat hidrasi & .800 & .154 & .843 & 5.204 & .000 \\
\hline
\end{tabular}

Jependent Variable: Volume latihan 
Berdasarkan tabel diatas, kita bisa melihat nilai sign sebesar 0,000 lebih kecil dari proabilitas 0,05 sehingga dapat disimpulkan bahwa Ho di tolak dan Ha diterima, yang berarti bahwa terdapat "pengaruh antara tingkat hidrasi dengan volume latihan". Dengan mengambil data status hidrasi dengan menampung urine atlet lalu dilanjutkan dengan mengambil data volume latihan dengan menghitung denyut jantung dengan cara menghitung denyut nadi permenit. Hasil analisis data penelitian menunjukkan bahwa atlet yang memiliki status hidrasi baik sebanyak 8 orang atau 62\% Dari jumlah sampel, sedangkan jumlah atlet yang memiliki status hidrasi sedang sebanyak 5 orang atau $38 \%$ dari sampel, dan tidak ditemukan atlet yang mengalami dehidrasi, Sedangkan untuk analisis data volume latihan menunjukkan bahwa atlet yang memiliki volume latihan tinggi sebanyak 9 atlet dari 13 atlet atau 69\% dari sampel, sedangkan atlet yang memiliki volume latihan menengah sebanyak 4 atlet dari 13 atlet atau 31\% sampel, dan atlet yang memiliki volume latihan rendah dan kurang tidak ada, Pengujian hipotesis menunjukkan nilai sign sebesar 0,000 lebih kecil dari proabilitas 0,05 sehingga dapat disimpulkan bahwa Ho di tolak dan Ha diterima, yang berarti bahwa terdapat "Pengaruh antara tingkat hidrasi dengan volume latihan". Putriana dalam Setiawati YN dkk (2012:49) menjelaskan bahwa atlet yang memulai latihan dengan status hidrasi yang baik belum tentu terhidrasi dengan baik pula setelah latihan. Status hidrasi yang baik dapat dicapai atlet dengan mengkonsumsi cairan yang cukup sebelum, selama dan setelah latihan. Pemberian cairan selama masa latihan dan pertandingan sangat penting untuk mempertahankan status dehidrasi atau menjaga keseimbangan air dan elektrolit. Sebuah penelitian di Brazil menunjukan bahwa 22\% atlet remaja ternyata masih mengkonsumsi air dibawah jumlah yang cukup Sousa, dalam Setiawati YN dkk (2012:49).

\section{Pembahasan}

Penelitian dilakukan pada minggu terakhir bulan Februari yakni tanggal 27, 28 dan tanggal 5,6 Maret. Dengan mengambil data status hidrasi dengan menampung urine atlet lalu dilanjutkan dengan mengambil data volume latihan dengan menghitung denyut jantung dengan cara menghitung denyut nadi permenit. Hasil analisis data penelitian menunjukkan bahwa atlet yang memiliki status hidrasi baik sebanyak 8 orang atau 62\% Dari jumlah sampel, sedangkan jumlah atlet yang memiliki status hidrasi sedang sebanyak 5 orang atau $38 \%$ dari sampel, dan tidak ditemukan atlet yang mengalami dehidrasi, Sedangkan untuk analisis data volume latihan menunjukkan bahwa atlet yang memiliki volume latihan tinggi sebanyak 9 atlet dari 13 atlet atau $69 \%$ dari 100\% sampel, sedangkan atlet yang memiliki volume latihan menengah sebanyak 4 atlet dari 13 atlet atau 31\% dari 100\% sampel, dan atlet yang memiliki volume latihan rendah dan kurang tidak ada. Pengujian hiipotesis menunjukkan nilai sign sebesar 0,000 lebih kecil dari proabilitas 0,05 sehingga dapat disimpulkan bahwa Ho di tolak dan Ha diterima, yang berarti bahwa terdapat "Pengaruh antara tingkat hidrasi dengan volume latihan". Putriana dalam Setiawati YN dkk (2012:49) menjelaskan bahwa atlet yang memulai latihan dengan status hidrasi yang baik belum tentu terhidrasi dengan baik pula setelah latihan. Status hidrasi yang baik dapat dicapai atlet dengan mengkonsumsi cairan yang cukup sebelum, selama dan setelah latihan. Pemberian cairan selama masa latihan dan pertandingan sangat penting untuk mempertahankan status dehidrasi atau menjaga keseimbangan air dan elektrolit. Sebuah penelitian di Brazil menunjukan bahwa $22 \%$ atlet remaja ternyata masih mengkonsumsi air dibawah jumlah yang cukup Sousa, dalam Setiawati YN dkk (2012:49). 


\section{Simpulan}

Berdasarkan hasil penelitian maka dapat disimpulkan bahwa : Atlet yang memiliki status hidrasi baik sebanyak 8 orang atau 62\% Dari jumlah sampel, sedangkan jumlah atlet yang memiliki status hidrasi sedang sebanyak 5 orang atau 38\% dari sampel, dan tidak ditemukan atlet yang mengalami dehidrasi, Atlet yang memiliki volume latihan tinggi sebanyak 9 atlet dari 13 atlet atau $69 \%$ dari $100 \%$ sampel, sedangkan atlet yang memiliki volume latihan menengah sebanyak 4 atlet dari 13 atlet atau 31\% dari 100\% sampel, dan atlet yang memiliki volume latihan rendah dan kurang tidak ada, Pada saat penelitian dan pengujian melalaui uji statistik, diketahui bahwa terdapat pengaruh yang signifikan antara tingkat hidrasi dengan volume latihan atlet, Hal ini di lihat dari Pengujian hiipotesis menunjukkan nilai sign sebesar 0,000 lebih kecil dari proabilitas 0,05 sehingga dapat disimpulkan bahwa Ho di tolak dan Ha diterima, yang berarti bahwa terdapat "Pengaruh antara tingkat hidrasi dengan volume latihan". Yang perlu disampaikan sehubungan dengan hasil penelitian ini, antara lain: perlunya pengaturan konsumsi cairan minuman pada atlet pada saat sebelum, selama dan setelah latihan. Perlunya peningkatan konsumsi cairan yang dapat meningkatkan cairan tubuh dan menghindari atau mengurangi konsumsi cairan yang dapat menyebabkan penurunan cairan tubuh. Selain itu, perlu mengedukasi atlet tentang pengetahuan konsumsi cairan dan status hidrasi sehingga atlet dapat mengatur konsumsi cairan agar dapat mempertahankan kondisi hidrasi baik.

\section{Daftar Pustaka}

Hariadi, N. (2018). Pengaruh Latihan Interval (Interval Training) Terhadap Peningkatanvo2max Tim Gama Fc Pancor 2017.

Irianto Djoko P. (2006). Panduan Gizi Lengkap Keluarga dan Olahragawan. Yogyakarta: Andi Offset.

Nurhidayat, N., Triadi, C., \& Fathurrahman, F. (2020). Tingkat Prestasi Akademik Ditinjau Dari Kebugaran Jasmani (Vo2 Max) Mahasiswa. Jurnal Porkes, 3(1), 26-30.

Ramdhan Reza I. (2016). Hubungan antara status hidrasi serta konsumsi cairn pda atlet Bola Basket Putra dan Putri Kejurda Kelompok Usia-18 tahun Kabupaten Indramayu.Skripsi.Fakultas Ilmu Keolahragaan.Universitas Negeri Yogyakarta.

Rismayanthi Cerika. (2014). Hubungan Antara Status Hidrasi dan Konsumsi cairan. Yogyayakarta. Fakultas Ilmu Keolahragaan.

Setiawati YN, Dkk. Desember 2012. "Identifikasi tingkat konsumsi air dan status Dehidrasi Atlet Pencak Silat Tapak Suci Putra Muhammadiyah Semarang”. Vol:7, No.2.

Siti Wardana K.N. (2014). Perbedaan Kebiasan Minum dan Status Hidrasi pada Remaja Overweight dan Non-Overweight di SMK Batik 1 Surakarta. Skripsi. Fakultas Ilmu Kesehatan, Universitas Muhammadiyah Surakarta.

Sugiyono, (2011). Metode Penelitian Pendidikan Pendekatan Kuantitatif, Kualitatif, dan R\&D. Bandung : Alfabeta.

Tirtawirya Devi, Februari 2012. Intensitas dan Volume Latihan dalam Olahraga. Jurnal Ilmiah Keolahragaan/jurnal ISSA, 1, 2252-3375. 